\title{
The relation between driving cognitions and driving phobia: The moderating role of emotional regulation strategies
}

\author{
Cornelia Măirean ${ }^{1}$ \\ ${ }^{1}$ Faculty of Psychology and Educational Sciences, Alexandru Ioan Cuza University of Iasi, Romania.
}

Received 11.09.2018; Received revised 13.12.2018; Accepted 17.12.2018

Available online 31.12.2018

\begin{abstract}
This study evaluated the relation between driving cognitions (i.e. panic, accidents, and social related cognitions) and driving phobia (driving fear and driving avoidance). We also investigated the moderating role of emotional regulation strategies (i.e. expressive suppression and cognitive reappraisal) in the relation between driving cognitions and driving phobia. A sample of 1401 drivers took part in this study $(51.8 \%$ men, Mage $=34.76, S D=11.76)$. The participants completed scales measuring driving cognitions, emotional regulation strategies, and driving phobia, as well as demographic information. The results showed that driving cognitions are positively associated with driving fear and driving avoidance. Further, our results revealed positive relations between expressive suppression and driving fear, as well as between cognitive reappraisal and driving avoidance. Moreover, driving related cognitions interacted with emotional regulation strategies in predicting driving fear. The implications of these results for interventions and future research are discussed.
\end{abstract}

Keywords: driving cognitions, expressive suppression, cognitive reappraisal, driving fear, driving avoidance.

Address of correspondence: Cornelia Măirean, Faculty of Psychology and Educational Sciences, Alexandru Ioan Cuza University of Iasi, Toma Cozma Street, No 3, Iasi, 700554, Romania.

E-mail: cornelia.mairean@uaic.ro

\section{Introduction}

Nonfatal injuries following motor vehicle accidents (MVCs) are well documented, with important economic and social consequences (Trógolo, Melchior, \& Medrano, 2014). Among the most common disorders following MVCs is driving phobia (Mayou \& Bryant, 2002), characterized by persistent fear of driving and the tendency to avoid driving stimuli (Ehlers et al., 2007). According to some studies, the percent of accident survivors who develop phobic travel anxiety is higher than of those who develop other mood disorders (Mayou, Tyndel, \& Bryant, 1997). Driving phobia can also develop subsequent to a minor MVC (Smith, Mackenzie-Ross, \& Scragg, 2007) or in samples who have not experienced a MVC (Taylor \& Deane, 2000; Taylor, Deane, \& Podd, 2000). Fear of driving is common in the general population and many people do not consider their involvement in a MVC as a source of their driving fear (Taylor \& Deane, 2000). Because these individuals drive with considerable distress or tend to avoid driving, driving phobia has many negative consequences, like restriction of freedom and of interpersonal functioning, or career impairments (Taylor, Deane, \& Podd, 2007). Moreover, individuals who drive despite their fear committee different traffic errors and engage in maladaptive traffic behaviors (e.g., attentional lapses, slowing for green lights, aggressive violations, driving far below the speed limit) that may place themselves and other traffic participants at risk of accidents (Clapp, Baker, Litwack, Sloan, \& Beck, 2014). Evidence of these negative consequences supports the necessity of investigating the factors associated with driving phobia.

Although many previous studies documented the risk factors for different phobias, little is known about the factors associated with driving phobia. Whereas different phobias share many common characteristics, the variables that lead people to be afraid of driving may be quite different than the factors associated with other types of phobia. Therefore, in order to bring evidence for the presence of this phenomenon, the purpose of the current study was to assess the factors related to driving phobia. Driving cognitions and emotional regulation strategies 
were taken into account, given their documented potential to lead to different anxiety disorders (Aldao, NolenHoeksema, \& Schweizer, 2010; Ehlers et al., 2007). The first aim of the current study is to assess the relation between driving related cognitions (i.e. panic related cognition, accident related cognition, and social related cognition) and driving phobia, including fear of driving and the tendency to avoid driving. These cognitions can contribute to driving fear, but little research investigated these relations, taking into account the two dimensions of driving phobia (Ehlers et al., 2007; Taylor et al., 2000; Taylor et al., 2007a). Further, given the important role of coping strategies in inadvertently maintaining different disorders, our second aim is to assess the relations between emotional regulation strategies (i.e. expressive suppression, cognitive reappraisal) and driving phobia. Third, we want to investigate the moderating role of emotional regulation strategies in the relation between driving related cognitions and driving phobia.

\section{Driving cognition and driving phobia}

According to cognitive theories of emotional disorders, distorted beliefs concerning threat and danger are involved in the development and maintenance of different phobias (e.g. Salkovskis, 1996). Individuals with specific phobias manifest biased information processing, with enhanced attention for fear-relevant information (Mogg \& Bradley, 2006) and the tendency to misinterpret neutral or ambiguous stimuli as a threat (Kolassa et al., 2007). As a consequence, anxiety-provoking cognitions can occur. The presence of these types of cognitions was documented in different types of phobias, like spider phobia (Jones \& Menzies, 2000), dental phobia (Muris, de Jongh, Merckelbach, Postema, \& Vet, 1998), or claustrophobia (Shafran, Booth, \& Rachman, 1993).

Previous findings showed that concerns regarding the dangerousness of travel, about having an accident, causing injury to self or others, about the risk of experiencing symptoms of panic anxiety, losing control over the car, or having no control over other people's driving behavior, as well as concerns about potentially embarrassing situations when driving have been linked with driving fear (Taylor et al., 2000). Based on these findings, Ehlers et al. (2007) developed a scale that measures three types of cognitions (panic, accident, and social cognitions) that may play a role in driving phobia. In their study, all the three cognitions correlated with the severity of driving phobia. However, during the last decade, few researchers addressed the relations between these cognitions and driving phobia (see Costa, Carvalho, Cantini, Freire, \& Nardi, 2014, for an exception). Moreover, so far, no study about the relations between driving cognitions and both driving fear and driving avoidance, have been published. Therefore, the first aim of the present study is to assess the relations between driving cognitions and driving phobia, manifested through fear and the tendency to avoid driving.

\section{Emotional regulation strategies and driving phobia}

Emotional regulation strategies have an important role in the development and maintenance of various mood and anxiety psychological disorders (Helbig-Lang, Rusch, \& Lincoln, 2015). These strategies can be defined as stable, individual differences in the way persons deal with their own emotional experiences (Liu, Prati, Perrewe, \& Brymer, 2010). One emotional regulation strategy that people use to cope with their emotions is expressive suppression, which involves attempts to inhibit or reduce ongoing emotional expressive responses. On the contrary, cognitive reappraisal consists of attempts to change the interpretation of a situation before the emotional responses have been completely triggered (Gross \& John, 2003). It was found that cognitive reappraisal is positively associated with low levels of psychopathology (Aldao et al., 2010), whereas expressive suppression has been associated with the development and maintenance of psychological disorders, including anxiety disorders (Bardeen \& Fergus, 2014). Moreover, difficulties in managing unwanted emotions have been associated with avoidant behaviors and with specific phobia (Lemaire, ElHage, \& Frangou, 2014).

Further, cognitive reappraisal was found to be useful in the treatment of social anxiety disorder (Kocovski, Fleming, Hawley, Ho, \& Antony, 2015) and of specific phobia (Hermann, Leutgeb, Scharmüller, Vaitl, Schienle, \& Stark, 2013). Taken together, there are some evidences that expressive suppression and cognitive reappraisal may be important features of phobia, but to our knowledge, no published study has examined whether these emotional regulation strategies predict the development of driving phobia. As well as a lack of information about the relations between emotional regulation strategies and driving phobia, an additional gap in the literature relates to whether coping strategies moderate the relations between cognitions and driving phobia. Therefore, the second aim of the present paper is to analyze the relations between emotional regulation strategies (i.e. expressive suppression and cognitive reappraisal) and driving phobia. Third, we examined whether emotional regulation strategies moderate the relations between driving cognitions and driving phobia.

\section{Method}

\section{Participants}

A total of 1401 Romanian drivers took part in this study. From the total of the sample, $51.8 \%$ were men. The participants' mean age is $34.76(S D=11.76)$ and they had been driving for 11.37 years on average (range $0-58, S D=$ 8.96 years). During their lifetime, the participants reported that they had been involved on average in .40 active accidents (range $0-7, S D=.83$ ), and in .77 passive accidents (range $0-18, S D=1.39$ ). Participants were selected from general population, the participation was voluntary, and only persons with a valid driving license were included in the study. There were no other exclusion criteria or restrictions based on demographic variables.

\section{Measures}

The Driving Cognitions Questionnaire (Ehlers et al., 2007 ) is a 20 -item scale that measures three areas of driving-related concerns: panic-related (e.g., My heart will stop beating), accident related (e.g., I will die in an accident), and social concerns (e.g., People will think I am a bad driver). Each item was rated according to how often each thought (i.e., item) occurs while driving, using a 5point Likert scale from 0 (Never) to 4 (Always). Higher scores indicated higher levels of dysfunctional cognitions. In the present study, the Cronbach Alphas are 0.78 for panic-related cognition, 0.79 for accident-related cognition, and 0.78 for social-related cognition.

The Travel Phobia Questionnaire (Ehring, Ehlers, \& Glucksman, 2006) is a 12 items assessing the severity of driving phobia symptoms. The participants were instructed 
to rate the statements concerning the situation they fear most/ find most difficult. The initial form of the items refers to fear or avoidance of driving a car/ travelling as a passenger/ riding a motorcycle or bicycle. We only assessed fear and avoidance of driving a car. A fear score (sum of the 6 fear items) and an avoidance score (sum of the 6 avoidance items) were computed. In the present study, the Cronbach Alphas for both fear (.79) and avoidance subscales (.85) were acceptable. Each item from fear subscale (e.g. I always feel frightened when I have to drive.) was rated using a 5-point Likert scale from 1 (Not at all) to 5 (Very strongly), while the items from avoidance subscale (e.g. I avoid driving a car in bad weather conditions.) were rated using a 5-point Likert scale from 1 (Never) to 5 (Always). Higher scores indicated higher levels of driving fear and driving avoidance. The participants rated how much each statement was true for them in the past month.

The Emotion Regulation Questionnaire (ERQ; Gross \& John, 2003) is a 10-item self-reporting scale designed to measure an individual's tendency to use cognitive reappraisal (six items: e.g. When I want to feel less negative emotions (such as sadness or anger), I change what I'm thinking about.) and expressive suppression (four items: e.g. I control my emotions by not expressing them.) to regulate emotions. Each item consists of a seven-point Likert scale ( 1 - strongly disagree; 7 - strongly agree). Higher scores indicated higher frequencies of using expressive suppression and cognitive reappraisal. In the present study, the Cronbach Alphas for both cognitive reappraisal (.72) and expressive suppression subscales (.71) were acceptable. Previous findings on Romanian population showed that ERQ presents good reliability and consistent correlations with measures of traumatic stress which supported the construct validity of the scale (Măirean \& Ceobanu, 2017).

The demographic questionnaire asked the participants to report their age, gender, their total mileage, the number of accidents they caused (i.e. active accidents), and the number of accidents they were engaged in, without being guilty (i.e. passive accidents).

\section{Procedure}

The study was approved by the Research Ethics Committee of Alexandru Ioan Cuza University of Iasi, Romania. The potential participants were contacted at their homes and via social media. They were informed about the scope of the study and about the fact that participation is voluntary and the information provided will be kept confidential. An informed consent form was signed and then the participants completed the self-report questionnaires.

\section{Statistical Analyses}

First, the correlations among the main study' variables were computed. Second, hierarchical regression models for driving fear and driving avoidance were conducted, with age and the overall number of kilometers in the first step, driving concerns in step two, cognitive reappraisal and expressive suppression in step three; the interactions between driving concerns and emotional regulation strategies were entered in the final step. The variables were centered to minimize multicollinearity. To examine the nature of the significant interaction terms, we used Dawson's (2014) method based on graphically display the interaction.

\section{Results}

\section{Associations among main study variables}

Descriptive statistics and the correlations between variables included in the study are presented in Table 1. The results revealed positive correlations between driving fear and panic $(r=.24 ; p<.001)$, accident $(r=.21 ; p<$ $.001)$, and social related cognitions $(r=.21 ; p<.001)$. Driving avoidance is also positively associated with panic $(r=.23 ; p<.001)$, accident $(r=.22 ; p<.001)$, and social cognitions $(r=.25 ; p<.001)$. Moreover, driving fear is positively associated with expressive suppression $(r=.06$; $p=.025)$, while driving avoidance is positively associated with cognitive reappraisal $(r=.07 ; p=.009)$. Based on Cohen's (2013) criteria for magnitude of effect sizes, the magnitude of all the above relationships ranges from very small to medium.

Table 1. Pearson correlations between main study variables

\begin{tabular}{|c|c|c|c|c|c|c|c|c|c|c|c|}
\hline & 1 & 2 & 3 & 4 & 5 & 6 & 7 & 8 & 9 & 10 & 11 \\
\hline 1. PC & 1 & & & & & & & & & & \\
\hline 2. $\mathrm{AC}$ & $.72 * * *$ & 1 & & & & & & & & & \\
\hline 3. $\mathrm{SC}$ & $.75 * * *$ & $.70 * * *$ & .1 & & & & & & & & \\
\hline 4. ES & .02 & .01 & .006 & 1 & & & & & & & \\
\hline 5. CR & $-.07 *$ & $-.08 * *$ & $-.05 *$ & $.19 * * *$ & 1 & & & & & & \\
\hline 6. DF & $.24 * * *$ & $.21 * * *$ & $.21 * * *$ & $.06^{*}$ & .03 & 1 & & & & & \\
\hline 7. DA & $.23 * * *$ & $.22 * * *$ & $.25 * * *$ & .01 & $.07 *$ & $.59 * * *$ & 1 & & & & \\
\hline 8. Age & $-.08 * *$ & $-.10 * * *$ & $-.15 * * *$ & $-.10 * * *$ & .02 & -.02 & .01 & 1 & & & \\
\hline 9. AA & .01 & .04 & .001 & .004 & $-.07 *$ & -.02 & -.04 & $.11 * * *$ & 1 & & \\
\hline 10. PA & -.02 & .01 & $-.05 *$ & .03 & $-.06^{*}$ & -.02 & $-.07 *$ & $.12 * * *$ & $.58 * * *$ & 1 & \\
\hline 11. Km & $-.06^{*}$ & $-.07 * *$ & $-.12 * * *$ & $.07 *$ & -.01 & $-.06^{*}$ & $-.09^{*}$ & $.26 * * *$ & $.23 * * *$ & $.26 * * *$ & 1 \\
\hline M & 2.39 & 3.81 & 3.21 & 12.70 & 21.65 & 8.41 & 10.17 & 34.76 & 0.40 & 0.77 & 232939.5 \\
\hline SD & 3.12 & 3.79 & 3.38 & 4.01 & 4.20 & 3.63 & 4.80 & 11.76 & 0.83 & 1.39 & 584508.5 \\
\hline
\end{tabular}

Note. PC - panic cognitions, AC - accident cognitions, SC - social cognitions, ES - expressive suppression, CR - cognitive reappraisal, DF - driving fear, DA - driving avoidance, AA - active accidents, PA - passive accidents, $\mathrm{KM}$ - the overall number of kilometers. $* p<.05, * * p<0.01, * * * p<.001$. 
Table 2. Hierarchical regression models of drivers' cognitions and emotions regulation strategies on driving fear

\begin{tabular}{|c|c|c|c|c|}
\hline & $\beta$ & $t$ & $\Delta R^{2}$ & $\Delta F$ \\
\hline \multicolumn{5}{|l|}{ Driving fear } \\
\hline Step 1 & & & 0.002 & 2.62 \\
\hline Age & -.002 & -0.07 & & \\
\hline $\mathrm{Km}$ overall & $-.06 *$ & -2.18 & & \\
\hline \multicolumn{5}{|l|}{ Step 2} \\
\hline Panic cognitions & $0.21 * * *$ & 4.28 & $.06^{* * *}$ & $19.62 * * *$ \\
\hline Accident cognitions & 0.05 & 1.26 & & \\
\hline Social cognitions & 0.03 & 0.83 & & \\
\hline Step 3 & & & $0.07 * * *$ & $15.33 * * *$ \\
\hline Expressive suppression & $0.05^{*}$ & 2.14 & & \\
\hline Cognitive reappraisal & 0.04 & 1.55 & & \\
\hline Step 4 & & & $0.08 * * *$ & $10.24 * * *$ \\
\hline Suppression x Panic cognitions & $-0.33 *$ & -2.27 & & \\
\hline Suppression $\mathrm{x}$ Accident cognitions & -0.15 & -1.06 & & \\
\hline Suppression x Social cognitions & $0.41 * *$ & 3.06 & & \\
\hline Reappraisal x Panic cognitions & $-0.52 *$ & -2.55 & & \\
\hline Reappraisal x Accident cognitions & $0.47 *$ & 2.22 & & \\
\hline Reappraisal x Social cognitions & -0.16 & -0.70 & & \\
\hline
\end{tabular}

Note. $* p<.05 ; * * p<.01 ; * * * p<.001$.

Table 3. Hierarchical regression models of drivers' cognitions and emotions regulation strategies on driving avoidance

\begin{tabular}{|c|c|c|c|c|}
\hline & $\beta$ & $t$ & $\Delta R^{2}$ & $\Delta F$ \\
\hline \multicolumn{5}{|l|}{ Driving avoidance } \\
\hline Step 1 & & & $0.009 * *$ & $7.28 * *$ \\
\hline Age & .04 & 1.43 & & \\
\hline $\mathrm{Km}$ overall & $-.10 * * *$ & -3.79 & & \\
\hline Step 2 & & & $0.07 * * *$ & $23.35^{* * *}$ \\
\hline Panic cognitions & 0.06 & 1.44 & & \\
\hline Accident cognitions & 0.06 & 1.67 & & \\
\hline Social cognitions & $0.16^{* * *}$ & 3.82 & & \\
\hline Step 3 & & & $0.08^{* * *}$ & $18.10 * * *$ \\
\hline Expressive suppression & -0.01 & -0.65 & & \\
\hline Cognitive reappraisal & $0.08 * *$ & 3.05 & & \\
\hline Step 3 & & & $0.08^{* * *}$ & $10.27 * * *$ \\
\hline Suppression $\mathrm{x}$ Panic cognitions & -0.14 & -1.00 & & \\
\hline Suppression $\mathrm{x}$ Accident cognitions & 0.13 & 0.95 & & \\
\hline Suppression x Social cognitions & 0.08 & 0.60 & & \\
\hline Reappraisal x Panic cognitions & -0.40 & -1.96 & & \\
\hline Reappraisal x Accident cognitions & 0.26 & 1.23 & & \\
\hline Reappraisal x Social cognitions & 0.13 & 0.57 & & \\
\hline
\end{tabular}

Note. ${ }^{*} p<.05 ; * * p<.01 ; * * * p<.001$.

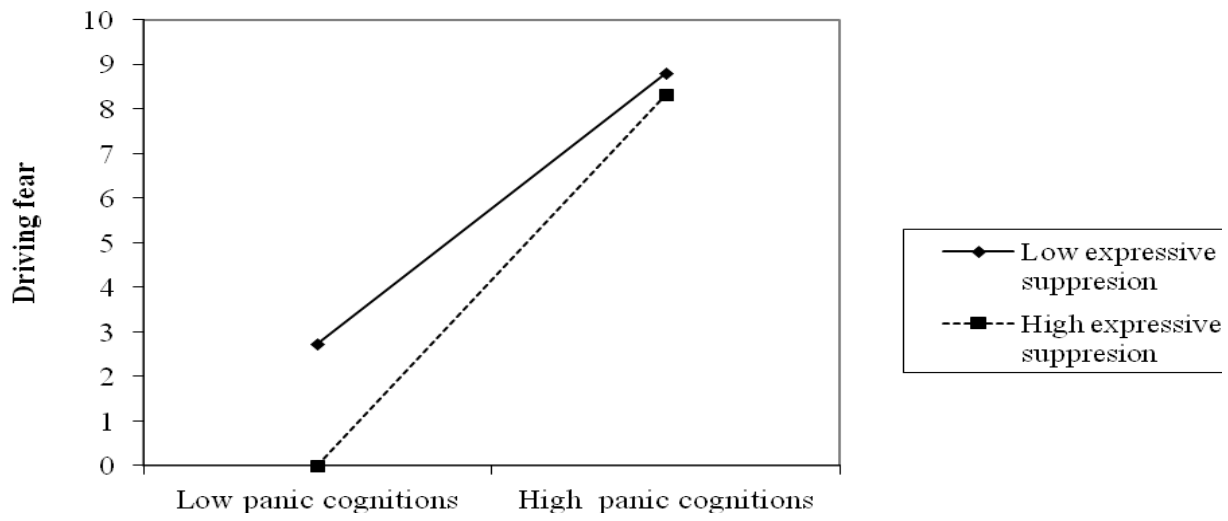

Figure 1. Presence of driving fear as a function of expressive suppression and panic cognitions 


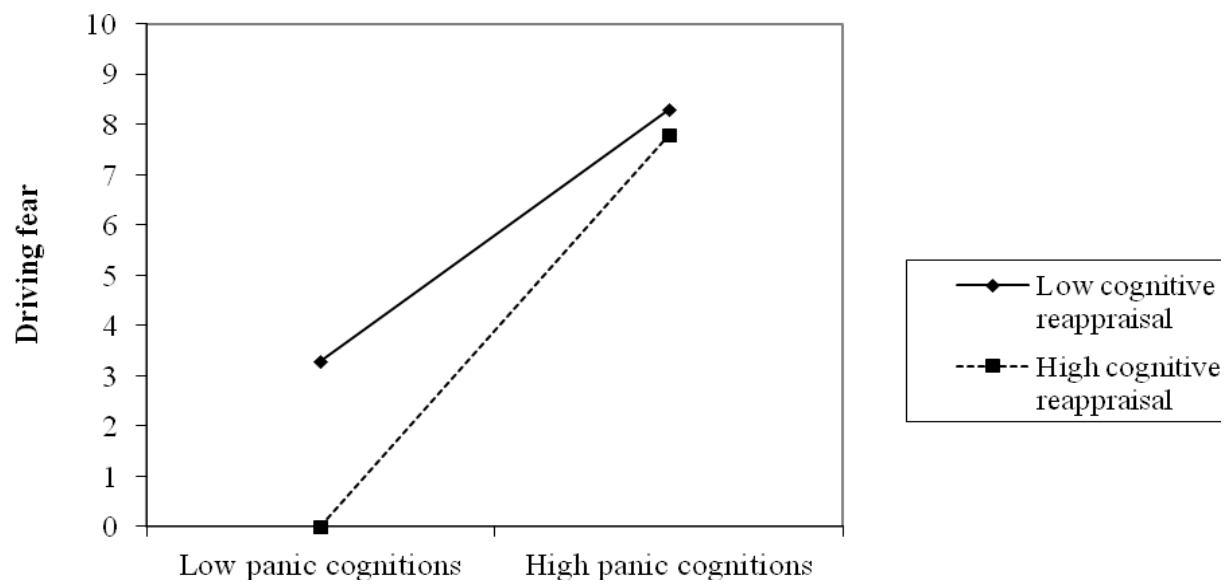

Figure 2. Presence of driving fear as a function of cognitive reappraisal and panic cognitions

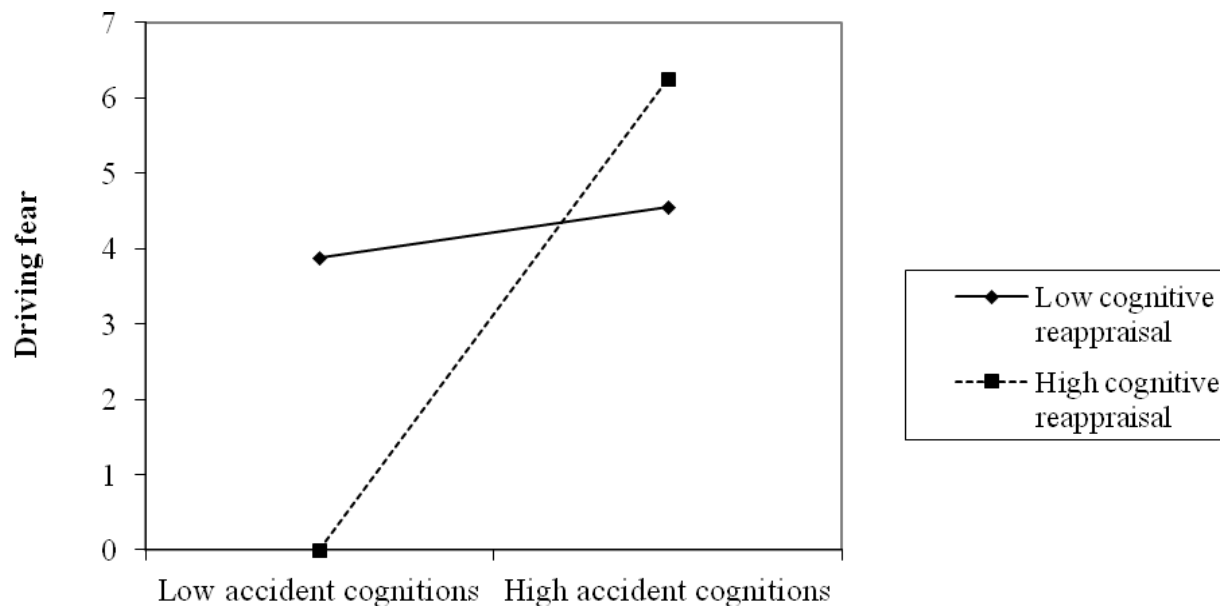

Figure 3. Presence of driving fear as a function of cognitive reappraisal and accident cognitions

\section{Moderation effects}

Hierarchical regression analysis was used to assess if driving cognitions interact with emotional regulation strategies in predicting driving fear and driving avoidance.

Driving fear is positively predicted by panic cognitions and expressive suppression. Furthermore, the interaction between expressive suppression and panic cognitions was significant in predicting driving fear. Moreover, the interactions between expressive suppression and social cognitions, cognitive reappraisal and panic cognitions, cognitive reappraisal and accident cognitions were also significant in predicting driving fear. These results are shown in Table 2.

Concerning the interaction between expressive suppression and panic cognitions, the simple slope analysis indicated that simple slopes for low (value of slope $=0.97$, $p<.001)$ and high $($ value of slope $=0.81, p<.001)$ level of expressive suppression are significantly different from zero (Dawson, 2014) (see Figure 1). On the contrary, for the interactions between expressive suppression and social cognitions, the simple slope is non-significant for both low (value of slope $=0.08, p=.725$ ) and high (value of slope $=$ $0.32, p=.093$ ) value of the moderator.

When analyzing the interaction between cognitive reappraisal and panic cognitions, the results showed significant simple slope for low (value of slope $=0.80, p<$ $.001)$ and high (value of slope $=0.63, p=.012$ ) level of the moderator (see Figure 2). Finally, for the interaction between cognitive reappraisal and accident cognitions, only the simple slope for high level of moderator is 
significant (value of slope $=0.25, p=.003$; low cognitive reappraisal: value of slope $=0.08, p=.317$ ) (see Figure 3).

Driving avoidance is positively predicted by social cognitions and cognitive reappraisal. The interactions between emotional regulation strategies and driving cognitions in predicting driving avoidance were non significant. The results are shown in Table 3.

\section{Discussion}

The present study investigated the relations of driving cognitions and emotional regulation strategies with driving phobia. Further, we explored the moderating role of emotional regulation strategies in the relation between driving cognitions and driving phobia.

Our results revealed that both driving fear and driving avoidance are positively associated with all the three driving cognitions studied - panic, accidents, and social related cognitions. Therefore, the present study confirmed the fact that beliefs concerning threat and danger are related to the development of phobias (e.g. Salkovskis, 1996). As well as spider-fearful individuals overestimate the probability and consequences of being bitten (Jones \& Menzies, 2000), driving-fearful individuals present concerns about being involved in an accident, about losing control and acting dangerously, or about being considered bad drivers by others. As in a previous study, a mixture of cognitions specific of panic disorder (e.g., not being able to think clearly), specific phobia (e.g., getting stuck in traffic), and social phobia (e.g., holding up traffic and people being angry) are related to driving phobia (Taylor et al., 2000). The results expand previous information, given the fact that they bring evidence on the relation between driving concerns and driving phobia, a less studied relation. Although some previous studies documented the relation between driving concerns and driving fear (Ehlers et al., 1994; Taylor et al., 2000), the relation between these cognitions and driving avoidance was neglected. Even if different phobias may share some common characteristics, it would be wrong to assume that the same factors are involved in the development of all the phobias. Driving phobia may be of particular importance given the fact that people may choose to drive despite their fear. These individuals are more prone to committee different traffic errors that may place themselves and other traffic participants at increased risk of being injured or even of losing their life (Clapp et al., 2014). Avoiding driving has also negative consequences, in terms of restriction of freedom (Taylor et al., 2007). In order to reduce these negative effects, it is important to identify the factors associated with driving phobia. Our results brought evidence for the fact that interventions designed to reduce driving phobia should address the driving related cognitions.

Further, our results showed that driving fear is positively associated with expressive suppression, while driving avoidance is positively associated with cognitive reappraisal, but these relations were very small. The relation between driving fear and expressive suppression was expected, given previous studies that documented the role of expressive suppression in the development of various anxiety psychological symptoms or disorders (Bardeen \& Fergus, 2014). The attempts to inhibit or reduce ongoing emotions leads to an ironic effect, consisting on exacerbating these emotions, given the fact that these attempts inhibit emotional processing and the habituation to emotional stimuli is not produced (Wenzlaff \& Wegner, 2000). Therefore, people who have the tendency to use suppression may experience an escalation of distressing emotions. Thus, driving fear is maintained and not reduced. Surprisingly is the relation between cognitive reappraisal and driving avoidance. Although very weak, the results showed a positive relation, and not negative, as expected, between these two variables. Previous studies found that cognitive reappraisal is useful in the treatment of social anxiety disorder (Kocovski et al., 2015), but our results suggest that in some cases this emotion regulation strategy can be associated with avoidance behaviors. Driving avoidance may be a coping strategy involuntary used in order to maintain the positive perspective about driving, created by cognitive reappraisal of the fearful situations. By avoiding driving activities, the risk of encounter stressful driving situations, which leads to negative emotions, is limited.

Another explanation for this result could rely on the fact that continue attempts to reevaluate stressful situations lead to a strong engagement with emotional aspects of the experience and this makes these experiences more salient. In order to reduce the discomfort associated with them, people may adopt other coping strategies, based on avoiding the stimuli associated with their negative affective state. Moreover, we cannot exclude the possibility that the participants generally use a negative reappraisal technique in order to control their emotions. Some items of the ERQ questionnaire did not necessarily reflect a positive cognitive reappraisal (e.g. I control my emotions by changing the way I think about the situation I'm in.) and it is possible that the participants to report their tendency to reappraise the experiences but not in a positive manner. Negative reappraisal is also possible and it is an ineffective way to reduce emotional distress (Cisler, Olatunji, Feldner, \& Forsyth, 2010). In order to clarify the role of this emotional regulation strategy, future studies should use instructed rather than dispositional cognitive reappraisal, in relation with driving phobia. Finally, some studies showed that people with phobia and people without phobia might use different tactics of cognitive reappraisal, based on distancing or on reinterpretation (Hermann et al, 2013). Thus, participants from our study may use cognitive reappraisal based on distancing, that further facilitate the occurrence of avoidance behaviors. Therefore, it is possible that previous results about the effectiveness of cognitive reappraisal may be dependent on the type of the sample. Given these possible explanations, we consider that the role of cognitive reappraisal in the development of driving phobia is unclear and should be addressed in future studies.

Furthermore, driving related cognitions interacted with emotional regulation strategies in predicting driving fear. High levels of accident cognitions are associated with high driving fear, for the participants with a high level of cognitive reappraisal. Moreover, when the level of panic cognitions is high, the driving fear is also high, regardless of the level of expressive suppression or cognitive reappraisal. However, for the participants with a low level of panic related cognitions, more driving fear is reported by the participants with a low tendency to use emotional regulation strategies (expressive suppression and cognitive reappraisal). Therefore, even a low level of driving concerns may be a risk factor for driving fear, for the participants that did not engage in emotional regulation strategies, such as expressive suppression and cognitive reappraisal. These results highlight the potential benefic role of cognitive reappraisal in emotional adjustment, for 
people confronting with low levels of dysfunctional panic cognitions. Contrary to many previous studies, the present results suggest that even expressive suppression may help drivers to diminish their driving fear, when they also present low levels of driving concerns. Thus, expressive suppression may not have detriments effects, when it is used for managing low levels of unwanted concerns. It may be associated with high levels of psychopathology, only for individuals with strong, negative emotions. However, the role of expressive suppression in driving fear should be tested longitudinally, given the fact that it can reduce the emotional distress on the moment but can facilitate the development in time of psychological disorders, including phobias (Bardeen \& Fergus, 2014).

The study has several limitations. First, these data are cross-sectional and we cannot establish the predictive power of the study' variables in terms of a temporal relationship. Additional longitudinal studies would be necessary to test whether driving related cognitions and emotional regulation strategies play a causal role in determining driving phobia. Second, we used a convenience sample in our study and the generalization of our findings should be made with caution. Third, the source of driving phobia was not taken into consideration. Although previous studies found that the experience of a driving accident is not necessary for the development of driving phobia (Smith et al., 2007; Taylor \& Deane, 2000; Taylor et al., 2000), future studies should aim to replicate these results in samples of MVAs' survivors. Moreover, future studies should consider the number and the injury severity of previous MVAs' as moderating variables in the relations between the risk factors and driving phobia's manifestations. Fourth, a limitation of our study consist on the fact that we did not measured comorbid diagnoses with driving phobia, like PTSD, panic disorder or social phobia, that may also contribute to these results. The presence of an additional disorder could exacerbate the driving concerns, which could further lead to a high level of driving phobia. Moreover, driving avoidance may be part of the widespread avoidance of a multitude of situations specific to PTSD. More controlled studies are needed to investigate the characteristics of people with driving phobia.

Despite the limitations presented above, our results can have important theoretical and practical implications. From a theoretical point of view, the present study brings further evidence for the less studied relations between driving cognitions and driving phobia. From a practical point of view, our results suggest that intervention strategies designed to reduce driving phobia should aim to identify and decrease driving related concerns. In a clinical context, it may be useful to assess which driving cognitions are most important for each individual.

As a conclusion, our results emphasize the associations between panic, accidents, social related driving concerns and driving phobia. Moreover, expressive suppression and cognitive reappraisal are related to the development of driving fear and driving avoidance. These emotional regulation strategies also moderate the relations between driving cognitions and driving fear. Future studies are needed in order to explain the determinants of driving phobia, for drivers with and without negative experiences on the road.

\section{ACKNOWLEDGEMENT}

This work was supported by a grant of Ministery of Research and Innovation, CNCS - UEFISCDI, project number PN-III-P1-1.1-PD-2016-0902, within PNCDI III.

\section{References}

Aldao, A., Nolen-Hoeksema, S., \& Schweizer, S. (2010). Emotion regulation strategies across psychopathology: A meta-analysis. Clinical Psychology Review, 30, 217-237. doi: 10.1016/j.cpr.2009.11.004

Bardeen, J. R., \& Fergus, T. A. (2014). An examination of the incremental contribution of emotion regulation difficulties to health anxiety beyond specific emotion regulation strategies. Journal of anxiety disorders, 28(4), 394-401. https://doi.org/10.1016/j.janxdis.2014.03.002

Cisler, J. M., Olatunji, B. O., Feldner, M. T., \& Forsyth, J. P. (2010). Emotion regulation and the anxiety disorders: An integrative review. Journal of Psychopathology and Behavioral Assessment, 32(1), 68-82. doi: 10.1007/s10862-009-9161-1

Clapp, J. D., Baker, A. S., Litwack, S. D., Sloan, D. M., \& Beck, J. G. (2014). Properties of the Driving Behavior Survey among individuals with motor vehicle accidentrelated posttraumatic stress disorder. Journal of Anxiety Disorders, 28(1), 1-7. doi: 10.1016/j.janxdis.2013.10.008

Cohen, J. (2013). Statistical power analysis for the behavioral sciences. New York: Lawrence Erlbaum Associates.

da Costa, R. T., de Carvalho, M. R., Cantini, J., da Rocha Freire, R. C., \& Nardi, A. E. (2014). Demographics, clinical characteristics and quality of life of Brazilian women with driving phobia. Comprehensive Psychiatry, 55(2), 374-379. doi: 10.1016/j.comppsych.2013.08.003

Dawson, J. F. (2014). Moderation in management research: What, why, when, and how. Journal of Business and Psychology, 29, 1-19. doi. 10.1007/s 10869-013-9308-7

Ehlers, A., Taylor, J. E., Ehring, T., Hofmann, S. G., Deane, F. P., Roth, W. T., \& Podd, J. V. (2007). The driving cognitions questionnaire: Development and preliminary psychometric properties. Journal of Anxiety Disorders, 21(4), 493-509. doi: 10.1016/j.janxdis.2006.08.002

Ehring, T., Ehlers, A., \& Glucksman, E. (2006). Contribution of cognitive factors to the prediction of posttraumatic stress disorder, phobia and depression after road traffic accidents. Behaviour Research and Therapy, 44, 1699 1716. doi: 10.1016/j.brat.2005.11.013

Gross, J. J., \& John, O. (2003). Individual differences in two emotion regulation processes: Implications for affect, relationships, and wellbeing. Journal of Personality and Social Psychology, $\quad 85(2), \quad 348 \quad-362$. http://dx.doi.org/10.1037/0022-3514.85.2.348

Helbig - Lang, S., Rusch, S., \& Lincoln, T. M. (2015) Emotion regulation difficulties in social anxiety disorder and their specific contributions to anxious responding. Journal of Clinical Psychology, 71(3), 241249. doi: $10.1002 /$ jclp. 22135

Hermann, A., Leutgeb, V., Scharmüller, W., Vaitl, D., Schienle, A., \& Stark, R. (2013). Individual differences in cognitive reappraisal usage modulate the time course of brain activation during symptom provocation in specific phobia. Biology of Mood \& Anxiety Disorders, 3(1), 16. doi: 10.1186/2045-5380-3-16

Jones, M. K., \& Menzies, R. G. (2000). Danger expectancies, self-efficacy and insight in spider phobia. Behaviour Research and Therapy, 38(6), 585-600. https://doi.org/10.1016/S0005-7967(99)00076-5

Jose, P. E. (2013). ModGraph-I: A programme to compute cell means for the graphical display of moderational analyses: 
The internet version, Version 3.0. Victoria University of Wellington, Wellington, New Zealand. Retrieved from http://pavlov.psyc.vuw.ac.nz/paul-jose/modgraph/

Kocovski, N. L., Fleming, J. E., Hawley, L. L., Ho, M. H. R., \& Antony, M. M. (2015). Mindfulness and acceptancebased group therapy and traditional cognitive behavioral group therapy for social anxiety disorder: Mechanisms of change. Behaviour Research and Therapy, 70, 11-22. doi: 10.1016/j.brat.2015.04.005

Kolassa, I. T., Buchmann, A., Lauche, R., Kolassa, S., Partchev, I., Miltner, W. H., et al. (2007). Spider phobics more easily see a spider in morphed schematic pictures. Behavioral and Brain Functions, 3, 59-74. doi: 10.1186/1744-9081-3-59

Lemaire, M., El-Hage, W., \& Frangou, S. (2014). Reappraising suppression: subjective and physiological correlates of experiential suppression in healthy adults. Frontiers in Psychology, 11, 5-571. doi: 10.3389/fpsyg.2014.00571

Liu, Y., Prati, M., Perrewe, P. L., \& Brymer, R. A. (2010). Dispositional differences in emotional regulation, emotional experiences at work, and work related outcomes; A two study investigation. Journal of Applied Social Psychology, 40(6), 515-1538

Măirean, C., \& Ceobanu, C. M. (2017). The relationship between suppression and subsequent intrusions: the mediating role of peritraumatic dissociation and anxiety. Anxiety, Stress, \& Coping, 30(3), 304-316. http://dx.doi.org/10.1080/10615806.2016.1263839

Mayou, R., \& Bryant, B. (2002). Outcome 3 years after a road traffic accident. Psychological Medicine, 32(4), 671-675. https://doi.org/10.1017/S0033291702005470

Mayou, R., Tyndel, S., \& Bryant, B. (1997). Long-term outcome of motor vehicle accident injury. Psychosomatic Medicine, 59(6), 578-584.

Mogg, K., \& Bradley, B. P. (2006). Time course of attentional bias for fear-relevant pictures in spider-fearful individuals. Behaviour Research and Therapy, 44, 1241-1250. doi: 10.1016/j.brat.2006.05.003

Muris, P., de Jongh, A., Merckelbach, H., Postema, S., \& Vet, M. (1998). Thought suppression in phobic and nonphobic dental patients. Anxiety, Stress, and Coping, 11, 275-287. http://dx.doi.org/10.1080/10615809808248315

Salkovskis, P. M. (1996). The cognitive approach to anxiety: Threat beliefs, safety-seeking behavior, and the special case of health anxiety and obsession. In P. M. Salkovskis (Ed.), Frontiers of cognitive therapy (pp. 48-74). New York: Guilford.

Shafran, R., Booth, R., \& Rachman, S. (1993). The reduction of claustrophobia-II: Cognitive analysis. Behaviour Research and Therapy, 31, 75-85. https://doi.org/10.1016/0005-7967(93)90045-V

Smith, B., Mackenzie-Ross, S., \& Scragg, P. (2007). Prevalence of poor psychological morbidity following a minor road traffic accident (RTA): The clinical implications of a prospective longitudinal study. Counselling Psychology Quarterly, 20(2), 149-155. http://dx.doi.org/10.1080/09515070701403679

Taylor, J. E., \& Deane, F. P. (2000). Comparison and characteristics of motor vehicle accident (MVA) and nonMVA driving fears. Journal of Anxiety Disorders, 14, 281-298. https://doi.org/10.1016/S0887-6185(99)00040-7

Taylor, J. E., Deane, F. P., \& Podd, J. V. (2000). Determining the focus of driving fears. Journal of Anxiety Disorders, $14, \quad 453-470 . \quad$ https://doi.org/10.1016/S08876185(00)00033-5

Taylor, J. E., Deane, F. P.,\& Podd, J.V. (2007). Driving fear and driving skills: Comparison between fearful and control samples using standardized on-road assessment. Behaviour Research and Therapy, 45, 805-818. https://doi.org/10.1016/j.brat.2006.07.007

Trógolo, M. A., Melchior, F., \& Medrano, L. A. (2014). The role of difficulties in emotion regulation on driving behavior. Journal of Behavior, Health \& Social Issues, 6(1), 107-117. doi: 10.5460/jbhsi.v6.1.47607

Wenzlaff, R. M., \& Wegner, D. M. (2000). Thought suppression. Annual Review of Psychology, 51(1), 59-91. doi: 10.1146/annurev.psych.51.1.59 